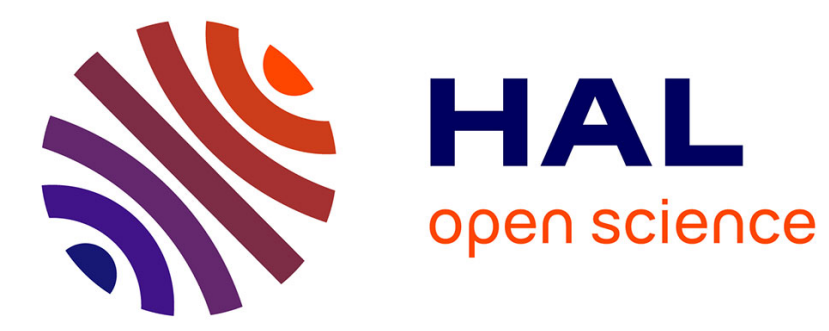

\title{
Short-time-scale specific heat experiments on smoky quartz
}

\author{
M. Saint-Paul
}

\section{To cite this version:}

M. Saint-Paul. Short-time-scale specific heat experiments on smoky quartz. Journal de Physique Lettres, 1980, 41 (7), pp.169-172. 10.1051/jphyslet:01980004107016900 . jpa-00231751

\section{HAL Id: jpa-00231751 https://hal.science/jpa-00231751}

Submitted on 1 Jan 1980

HAL is a multi-disciplinary open access archive for the deposit and dissemination of scientific research documents, whether they are published or not. The documents may come from teaching and research institutions in France or abroad, or from public or private research centers.
L'archive ouverte pluridisciplinaire HAL, est destinée au dépôt et à la diffusion de documents scientifiques de niveau recherche, publiés ou non, émanant des établissements d'enseignement et de recherche français ou étrangers, des laboratoires publics ou privés. 


\title{
Short-time-scale specific heat experiments on smoky quartz
}

\author{
M. Saint-Paul \\ Centre de Recherches sur les Très Basses Températures, \\ C.N.R.S., BP 166 X, 38042 Grenoble Cedex, France \\ (Reçu le 18 septembre 1979, révisé le 21 janvier, accepté le 8 février 1980)
}

\begin{abstract}
Résumé. - Des mesures de chaleur spécifique en temps courts ont été effectuées sur des échantillons de quartz naturel irradiés par rayonnement gamma. Elles ont été réalisées avec des temps de l'ordre de la milliseconde aux températures de l'hélium liquide. Une réduction de la chaleur spécifique a été mise en évidence dans cet intervalle de temps entre $1,4 \mathrm{~K}$ et $4,2 \mathrm{~K}$.
\end{abstract}

\begin{abstract}
Short-time-scale specific heat measurements have been performed on gamma irradiated natural quartz crystals in the millisecond time-scale at liquid helium temperatures. Evidence for a reduction of the specific heat has been observed in this time-scale between $1.4 \mathrm{~K}$ and $4.2 \mathrm{~K}$.
\end{abstract}

1. Introduction. - It is well known that in $\gamma$ irradiated natural quartz a hole (electron defect) is trapped at an oxygen site near a substitutional aluminium impurity [1]. Experimental data support the idea that at low temperatures the hole moves in a double well potential in which the particle may tunnel through the potential barrier between two inequivalent minima associated with the two oxygen ions nearest to an aluminium impurity [2,3], generating a two level system (TLS). Random electric fields due to ionized defects and local strains result in a broad distribution $N(E)$ of the energy splittings, confirmed by the large linearly temperature-dependent contribution to the specific heat $[4,5]$, and by the dielectric results $[2,5]$. A localization temperature $T_{\mathrm{L}}$ proportional to the width of the distribution is estimated to vary between 2 and $9 K[2,5] . T_{L}$ characterizes the degree of imperfection of the crystal. The long dielectric relaxation time $\left(T_{1} \approx 10^{-3} \mathrm{~s}\right.$ at $\left.4 \mathrm{~K}\right)$ suggests that the electronic defects are weakly coupled to the lattice phonons. Moreover, the thermal conductivity is unchanged in comparison with non-irradiated quartz below $1 \mathrm{~K}$ [5, 7], and no resonant absorption is detected in high frequency ultrasonic attenuation experiments [6].

A consequence of the tunneling model is that the specific heat should depend on the time-scale of measurement $t$ because the defects with relaxation time $T_{1}$ longer than $t$ will not influence the measurements, leading to a reduction in the apparent specific heat.

We report results obtained with a heat pulse techni- que performed on a sample of natural quartz irradiated with gamma rays at a dose of $10^{7} \mathrm{rad}$. A transient behaviour of the temperature is observed in the millisecond time-scale. Such an effect is not observed with the same sample submitted to a thermal bleaching for two hours at $400{ }^{\circ} \mathrm{C}$. The experimental results are compared with the dielectric and long-time specific heat results obtained with the same sample [5].

2. Experimental set-up. - The sample is a disk (15 $\mathrm{mm}$ in diameter, $1 \mathrm{~mm}$ in thickness) cut from a natural quartz sample furnished by the Valpey Fisher Corporation. It was irradiated at room temperature with gamma rays at a dose of $10^{7} \mathrm{rad}$. The same sample (sample 1 in Ref. [5]) was used previously in longtime specific heat and dielectric measurements $[4,5]$; the impurity content is mainly aluminium at a concentration of $37 \mathrm{ppm}$. The heater and thermometer are thin films made by spraying a colloidal suspension of graphite across evaporated electrical contacts. The internal time constants are short, about $100 \mu \mathrm{s}$ [9]. The electrical resistance of each is about $500 \Omega$ at liquid helium temperatures. The time constant of the electronic measurement system is less than $100 \mu \mathrm{s}$. The sample is mechanically pressed against the cold source in an evacuated chamber of a ${ }^{4} \mathrm{He}$ cryostat [8]. The external thermal time constant is about $0.2 \mathrm{~s}$. An electrical pulse of about $2 \mathrm{~V}$ height and $20 \mu \mathrm{s}$ width is applied to the heater. The resistance of the detector is measured by having a constant $10 \mu \mathrm{A}$ bias current and monitoring the voltage [9]. The 
change of voltage due to the heat pulse is viewed on a storage oscilloscope at a repetition rate of about $1 \mathrm{~Hz}$. The temperature of the cold source is measured with a carbon resistor. The temperature rise of the sample is about $10 \%$ with a heat pulse energy of about 1 erg.

Temperature rises observed on the storage oscilloscope at different temperatures of the cold source are shown in figure 1 . Our experimental time scale is 1

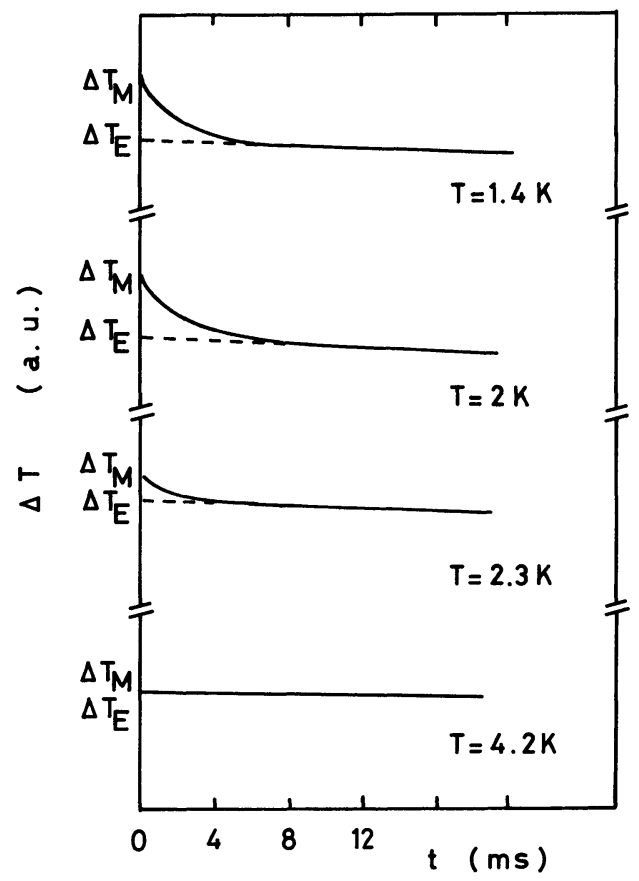

Fig. 1. - The temperature rises recorded after a heat pulse was applied at the initial time $t=0$ are given in figure 1 with arbitrary units (a.u.) at different temperatures.

to 3 orders of magnitude slower than in recent published experiments $[10,11]$. No sophisticated treatment of the signal has been performed, and the parameters have been deduced directly from the experimental curves displayed on the storage screen. It has been checked many times that the amplitude of the transient $\Delta T_{\mathrm{M}}-\Delta T_{\mathrm{E}}$ decreases when the mean temperature of the sample increases above $1.3 \mathrm{~K}$, with all other experimental conditions maintained constant. It has also been checked experimentally that this transient is not observed on the same sample after it has been submitted to a thermal annealing for 2 hours at $400{ }^{\circ} \mathrm{C}$. The thermal phonons are in thermal equilibrium in the millisecond time-scale $t ; t$ is four orders of magnitude larger than the phonon relaxation time for boundary scattering.

3. Experimental results. - Experimental temperature rises $\Delta T$ due to short heat pulses applied at initial time $t=0$ are shown in figure 1 for the irradiated sample. Each curve corresponds to a constant temperature of the cold source. At the lowest temperatures a short-time transient contribution to $\Delta T$ is observed in the millisecond time range. The slow time variation of $\Delta T$ is the thermal relaxation between the sample and the cold source with a thermal time constant of about $0.2 \mathrm{~s}$. The amplitude of the short-time contribution decreases continuously when the mean temperature of the sample increases, and vanishes completely around $4 \mathrm{~K}$.

The parameters $\Delta T_{\mathrm{M}}$ and $\Delta T_{\mathrm{E}}$ are defined in figure 1 . $\Delta T_{\mathrm{M}}$ is the temperature rise about $100 \mu \mathrm{s}$ after the end of a heat pulse, and $\Delta T_{\mathrm{E}}$ is the value extrapolated to the initial time $t \approx 0$ from the slow variation of $\Delta T$. The values of $\Delta T_{\mathrm{M}} / \Delta T_{\mathrm{E}}$ obtained at different temperatures are given in table I. The values of $C_{\mathrm{ir}} / C_{\mathrm{ph}}$ deduc-

Table I. $-\Delta T_{\mathrm{M}}$ is the value of the temperature rise at the initial time $t=0$ in figure 1 .

$-\Delta T_{\mathrm{E}}$ is the value of the slow variation extrapolated to the initial time $t=0$ in figure 1 .

$-C_{\mathrm{ir}}$ is the specific heat measured in the same irradiated sample (sample 1 of Ref. [5]) in the long-time experiment given in references $[4,5] . C_{\mathrm{ir}}$ is the sum of the TLS and lattice contributions, $C_{\mathrm{ir}}=C_{\mathrm{ph}}+C_{\mathrm{T}}$. The lattice contribution $C_{\mathrm{ph}}$ have been measured in the nonirradiated crystal Refs. [4, 5].

$\begin{array}{lll}T(\mathrm{~K}) & \frac{\Delta T_{\mathrm{M}}}{\Delta T_{\mathrm{E}}} & \frac{C_{\mathrm{ir}}}{C_{\mathrm{ph}}} \\ - & - & - \\ 1.4 & 1.7 & 2 \\ 1.5 & 1.4 & 1.6 \\ 2 & 1.3 & 1.3 \\ 2.3 & 1.2 & 1.28 \\ 4.2 & 1 & 1\end{array}$

ed from the long-time specific heat results are reported in the same table $\mathrm{I}$. $C_{\mathrm{ph}}$ is the lattice contribution obtained without irradiation, and $C_{\mathrm{ir}}$ is the longtime specific heat measured with the same irradiated sample (sample 1 in Ref. [5]). The values in columns 2 and 3 of table I agree to within the experimental accuracy of $20 \%$; both decrease progressively to 1 when the temperature increases up to $4.2 \mathrm{~K}$.

The short-time transient contribution to $\Delta T$ in the millisecond time range is deduced by substracting the extrapolated slow-time contribution. It can be fitted within experimental accuracy with a single exponential function with a time constant $\tau_{\text {th }}$ of about $2 \times 10^{-3} \mathrm{~s}$.

We define the time constant $\tau$ by :

$$
\tau=\tau_{\mathrm{th}} \cdot \frac{\Delta T_{\mathrm{M}}}{\Delta T_{\mathrm{E}}}
$$

$\tau$, deduced from the values of $\tau_{\mathrm{th}}$ and $\Delta T_{\mathrm{M}} / \Delta T_{\mathrm{E}}$, is shown in figure 2 for different temperatures. The experimental values of $\tau$ are inversely proportional to the temperature, and in agreement with the values of the relaxation time obtained in dielectric measurements (Fig. 4 of Ref. [5]). 


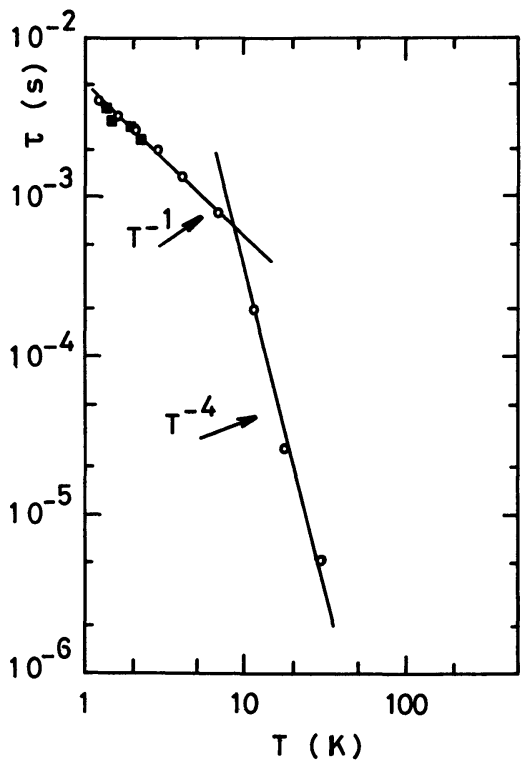

Fig. 2. - The time constants obtained by the relation (1) defined in the text, ( $\square$ ) together with dielectric time constants (o) (fig. 4 of Ref. [5]) at different temperatures.

4. Discussion. - The results obtained in the longtime specific heat measurements with the same sample permit an analysis of the time variation of the temperature rise $\Delta T$.

The specific heat $C_{\mathrm{ir}}$ of the irradiated sample is the sum of the tunneling level contribution $C_{\mathrm{T}}$ and the phonon contribution $C_{\mathrm{ph}}, C_{\mathrm{ir}}=C_{\mathrm{T}}+C_{\mathrm{ph}}$. $C_{\mathrm{T}}$ increases linearly with temperature below $1 \mathrm{~K}$ and shows a broad bump around $2 \mathrm{~K}[4,5]$. The values of $C_{\mathrm{ir}} / C_{\mathrm{ph}}$ at the temperatures of interest are given in table $\mathrm{I}$.

The thermal conductivity $K$ shows a nearly $T^{3}$ dependence below $3 \mathrm{~K}$ due to scattering of phonons by the sample boundaries [5, 6]. The thermal diffusivity of the sample is characterized by a time $t_{\mathrm{R}} \approx D^{-1} L^{2}$, where the length of the sample, $L$, is $1 \mathrm{~mm}$. The diffusivity $D$ obtained from $K$ gives $t_{\mathrm{R}} \sim 10^{-7} \mathrm{~S}$ around $1 \mathrm{~K}$. Consequently the temperature becomes uniform through the sample if the timescale $t$ is larger than this value. This condition is obviously satisfied in the millisecond range. Any further time dependence in the millisecond time range of the temperature rise $\Delta T$ due to heat pulses must be attributed to an increase of the specific heat resulting from tunneling levels with long-time constants coming in to thermal equilibrium with the lattice.

The temperature rises $\Delta T_{\mathrm{M}}$ and $\Delta T_{\mathrm{E}}$ are directly connected to the lattice $\left(C_{\mathrm{ph}}\right)$ and defect $\left(C_{\mathrm{T}}\right)$ contributions. In the long-time limit, $t \gg T_{1}$, all the defects are in thermal equilibrium with the lattice. The temperature rise produced by a heat pulse of energy $q$ is $q /\left(C_{\mathrm{ph}}+C_{\mathrm{T}}\right)$, equal to $\Delta T_{\mathrm{E}}$. In the short-time limit, $10^{-7} \mathrm{~s} \ll t \ll T_{1}$, the lattice absorbs all the energy $q$ and its temperature rise is $q / C_{\mathrm{ph}}$ equal to $\Delta T_{\mathrm{M}}$ measured at $\approx 100 \mu$ s (Fig. 1).
The ratio of the temperature rises in the two limits is therefore :

$$
\frac{\Delta T_{\mathrm{M}}}{\Delta T_{\mathrm{E}}}=\frac{C_{\mathrm{ph}}+C_{\mathrm{T}}}{C_{\mathrm{ph}}} .
$$

The relation (2) is well satisfied by the experimental results, as shown in table $I$.

The time dependence of the temperature rise $\Delta T$ observed within the sample (Fig. 1) is analysed with the tunneling model $[12,13]$. Defects characterized by a time constant $T_{1}$ come in to thermal equilibrium for experimental times $t$ comparable to $T_{1}$; in that time range $\Delta T$ must change with $t$. The thermal equations have been analysed in detail $[12,13]$. Here we need the case where the temperature is homogeneous through the sample. The dynamic specific heat of defects with a density of states $N(E)$ and a relaxation rate $T_{1}^{-1}$ is given at frequency $S$ and temperature $T$ by

$$
C_{\mathrm{T}}(S)=\int_{0}^{\infty} k\left(\frac{E}{2 k T}\right)^{2} \frac{1}{\mathrm{Ch}^{2}(E / 2 k T)} \frac{N(E) \cdot \mathrm{d} E}{\left(1+S T_{1}\right)}
$$

The relaxation time $T_{1}$ at temperature $T$ (larger than $E / k)$ varies linearly with $T^{-1}$

$$
T_{1} \approx \frac{\pi \hbar^{4} \rho \bar{c}^{5}}{\bar{B}^{2} \Gamma^{2} k} \cdot \frac{1}{T}
$$

where $\bar{B}$ is the mean coupling between defects and phonon, $\Gamma$ is the tunnel splitting of defects, $\bar{c}$ is the mean sound velocity and $\rho$ is the quartz density. The other parameters have their usual meaning. The coefficient relating the dielectric relaxation time to $T^{-1}$ is $5.56 \times 10^{-3} \mathrm{sK}$ (Fig. 2). The dielectric relaxation time is not distributed in the temperature range $1 \mathrm{~K}-4 \mathrm{~K}$, the width of the dielectric curve is comparable with that of a Debye curve $[2,5]$.

The time dependence of $\Delta T$ is deduced from the Laplace transform equation :

$$
S \tilde{\Delta T}=\frac{\tilde{\delta q}}{\delta t}\left[C_{\mathrm{ph}}+C_{\mathrm{T}}(S)\right]^{-1}
$$

where $\tilde{\Delta T}$ is the Laplace transform of $\Delta T$. Numerical calculations were performed using the gaussian distribution $N(E)=N(0) \quad \exp -\left(E / k T_{\mathrm{L}}\right)^{2}$ with

$$
N(0)=1.6 \times 10^{46} \mathrm{MKS}
$$

and $T_{\mathrm{L}}=6 \mathrm{~K}$. Both numbers are deduced from the long-time specific heat measurements $[4,5]$. The most important contribution to $C_{\mathrm{T}}(S)$ is due to the defects which have a relaxation time $T_{1}$ given by relation (4), so that all defects can be considered to have the same time constant $T_{1}$ at a given temperature $T . \Delta T$ deduced from (5) gives an exponential variation :

$$
\Delta T(t)=\frac{q}{C_{\mathrm{ph}}}\left[\frac{C_{\mathrm{ph}}}{C_{\mathrm{ph}}+C_{\mathrm{T}}}+\frac{C_{\mathrm{T}}}{C_{\mathrm{ph}}+C_{\mathrm{T}}} \mathrm{e}^{-t / \tau_{\mathrm{th}}}\right]
$$


with

$$
\tau_{\mathrm{th}}=\frac{C_{\mathrm{ph}}}{C_{\mathrm{ph}}+C_{\mathrm{T}}} \cdot T_{1}
$$

Expression (6) is in agreement with the exponential time variation $\Delta T$ observed in the millisecond time range and also with the experimental values obtained in the short- and long-time limits (table I).

In conclusion, there is evidence that the time dependence of the temperature rise $\Delta T$ observed in the millisecond time range results from the time dependence of the specific heat of tunneling defects. The tunneling model described in reference [2] explained both specific heat and dielectric properties which are caused by the same kind of electronic defects trapped at aluminium impurities $[2,4,5]$. The relatively long relaxation time $T_{1}$ of the known defects means that the time dependence of the specific heat predicted by the tunneling model is detectable without too much difficulty, as opposed to the case of complex amorphous systems $[10,11]$.

Acknowledgments. - We want to thank J. Chaussy for helpful discussions and P. Brosse-Maron for his expert technical assistance.

\section{References}

[1] For an extensive bibliographical review, see WEIL, J. A., Radiat. Eff. 26 (1975) 261.

[2] DE Vos, W. J. and Volger, J., J. Physica 47 (1970) 13

[3] Schnadt, R. and Schneider, J., Phys. Kondens. Mater. 11 (1970) 19.

[4] Saint-Paul, M., Picot, B. and Nava, R., Phys. Lett. 66A (1978) 389.

[5] Chaussy, J., Gilchrist, J. le G., Lasjaunias, J. C., SaintPaul, M. and Nava, R., J. Phys. Chem. Solids 40 (1979) 1073.

[6] Saint-Paul, M. and Nava, R., J. Physique 39 (1978) 786.

[7] Wasim, S. and Nava, R., Phys. Status Solidi (a) 51 (1979) 359.
[8] Chaussy, J., to be published.

[9] Cannon, W. C. and Chester, M., Rev. Sci. Instrum. 38 (1967) 318.

Korcynsky, Y., Sherlock, R. A., Wyatt, A. F. G., Proceedings of LT 14 (1975).

[10] Goubeau, W. M. and TaIt, R. A., Phys. Rev. Lett. 34 (1975) 1220.

[11] Kummer, R. B., Dynes, R. C. and Narayamurti, V., Phys. Rev. Lett. 40 (1978) 1187.

[12] Black, J. L., Phys. Rev. B17 (1978) 2740

[13] Rammal, R., Thèse Université Grenoble (1977) (unpublished). 